\title{
Anatomical observations of the foramina transversaria
}

\author{
C. T A I T Z, H. N A T H A N, A N D B. A R E N S B U R G
}

From the Department of Anatomy and Anthropology, Sackler School of Medicine, Tel-Aviv University, Ramat-Aviv, Israel

SUMMARY Four hundred and eighty foramina transversaria in dry cervical vertebrae of 36 spines and in a number of dissections were studied and classified according to size, shape, and direction of their main diameter. A coefficient of roundness was then elaborated. The variations of foramina appear to follow a pattern at various vertebral levels. The possible factors (in addition to the embryological ones) involved in causing these variations-for example, mechanical stress, size, course, and number of the vertebral vessels-were analysed. The importance of the correct interpretation of the variations in the foramina transversaria in radiographic or computerised axial tomography is discussed. The contribution of the present study to the understanding and diagnosis of pathological conditions related to the vertebral artery and its sympathetic plexus is stressed.

Observations have been made on the variability of size and form, duplication, or even absence of one or more of the foramina transversaria of the spinal column (Anderson, 1968; Jaen, 1974). The foramina transversaria (FT) transmit the vertebral vascular bundle (vertebral artery, and veins) and the sympathetic plexus which accompanies the vessels. Derangements of these structures in their course because of narrowing or deformation of the foramina, or osteophytes impinging on them, have been extensively investigated (Kovacs, 1955; Tatlow and Bammer, 1957; Hadley, 1958; Sheehan et al., 1960; Hyyppa et al., 1974). The importance of such disturbances to these vital vessels and nerves is obvious. The present work provides material for a more accurate interpretation of the radiographic pictures, angiograms, and especially the newer CAT pictures.

\section{Anatomical considerations}

The foramen transversarium is the result of the special formation of the cervical transverse processes. It is formed by a vestigial costal element fused to the body and the originally true transverse process of the vertebra; the vertebral vessels and nervous plexus are caught between the bony parts.

The FT is closed laterally by the "costotransverse bar", a plate of bone interconnecting the rib element to the original transverse process. This Accepted 13 September 1977

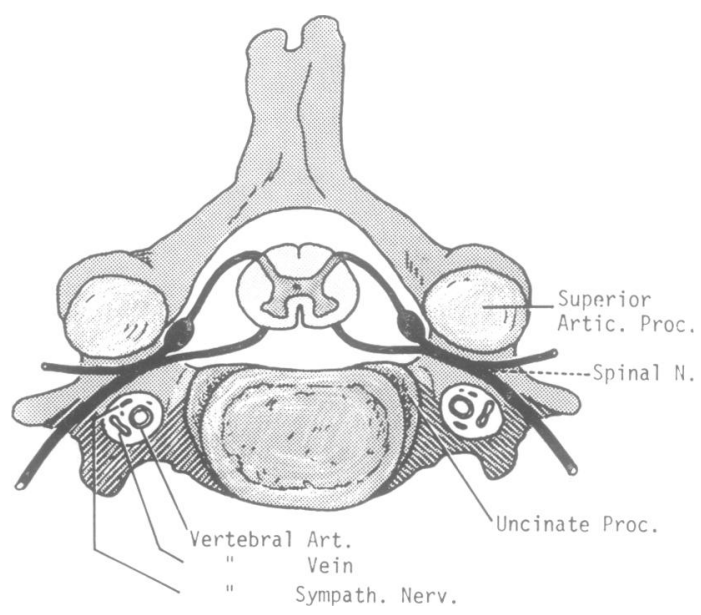

Fig. 1 Schematic cervical vertebra: shows the foramen transversarium with the various structures passing through it. Shaded portion of transverse process represents rib component.

plate is grooved in its upper aspect. The cervical spinal nerves, after emerging from the intervertebral foramen, cross the vertebral vessels posteriorly; the anterior ramus of the nerve proceeds in its course laterally and downwards in the groove of the costotransverse bar (Fig. 1). Haglund (1942) and Exner (1954) have described cases where vertebral arteries showed indentations produced by the spinal nerves. 
The FT is normally present in the transverse processes of all the cervical veriebrae. However, the vertebral artery starts to thread the FT only from the sixth FT upwards to the atlas, and the seventh foramen is normally occupied only by the vein or veins.

\section{Material and methods}

We studied 480 FT in dry cervical vertebrae of 36 spines. The material belonged to adult males and females, and had been imported from India for teaching purposes. A number of dissecting room cadavers were also studied in order to correlate the course and size of the vertebral arteries through the foramina transversaria. Vertebrae from archaeological excavations in Israel (from various periods) were also examined. ${ }^{1}$

According to the shape and direction of the main diameter, the FT were classified into five types (the vertebra were studied as seen from above in an A-P direction, the body of the vertebra facing the examiner): type 1 round, type 2 elliptical with main diameter (length) anteriorposterior, type 3 elliptical with main diameter transversal (breadth), type 4 elliptical with main diameter oblique, from right to left (see Table 1), type 5 elliptical with main diameter oblique, from left to right (Table 1).

Measurements of the FT were taken with calipers. Based on the maximal and minimal diameters of the FT, an index of these two values (coefficient of roundness) was calculated as max. breadth $X$ 100 max. length, and classified accordingly as:

1. Brachymorph-more than 85 (maximal roundness 100 ).

2. Mesomorph-between 75-85.

3. Dolichomorph-less than 75 .

It must be noted that the FT of the axis (C2) is different from the foramina of the other vertebrae in that it is not a simple short foramen, but an angulated canal with two openings, inferior (I) and

1 These vertebrae were not included in the calculation of the tables; only one special vertebra is described and presented here. lateral (L), very often of different characteristics. For this reason, the two openings were analysed separately.

\section{Observations and description}

The frequency of the different types of the foramina transversaria in each side of the vertebra is shown in Table 1.

It can be seen that:

1. The atlas shows the highest frequency of types 4 and 5 for right and left FT.

2. The lateral aperture of the axis is predominantly type 1 , in contrast to the interior aperture where types 4 and 5 predominate.

3. The FT of vertebrae $\mathrm{C} 3, \mathrm{C} 4$, and $\mathrm{C} 5$ show a high frequency of type 3 (the left FT of C5 vertebra show an equal prevalence of type 1).

4. C6 FT are mainly of type 1 but the right FT show an equal prevalence of type 3 .

5. C7 FT shows a preponderance of types 4 and 5 .

Table 2 presents the minimal and maximal mean values for the length and breadth of the foramina transversaria in each side of the various vertebrae.

Table 2 shows that the FT of the atlas have the highest mean value, while C7 FT show the lowest value, the mean values for the FT from vertebral levels $\mathrm{C} 3$ to $\mathrm{C} 7$ are seen to be higher on the left side than on the right, and the coefficient of variation of the FT increases (from cranial to caudal) from vertebra $\mathrm{C} 4$ to $\mathrm{C} 7$ (inclusive).

Figure 2 illustrates the distribution of the mean indices of the foramina transversaria in each side of the various vertebrae. This shows that the great majority of FT in both sides fall into the category of mesomorph, dolichomorph are found in the FT of C7 vertebra only, and brachymorph are seen in FT of C5, C6 vertebrae and in the lateral aperture of the axis of the left side only.

\section{Single small foramen}

Eight vertebrae were observed to have a single FT of too small a dimension to be measured with

Table 1 Frequency of the different types of the foramina transversaria in each side of the vertebrae

\begin{tabular}{|c|c|c|c|c|c|c|c|c|c|c|c|c|c|c|c|c|}
\hline \multirow{2}{*}{$\begin{array}{l}\text { Shape and } \\
\text { direction } \\
\text { of axes }\end{array}$} & \multicolumn{2}{|l|}{$\mathrm{Cl}$} & \multicolumn{2}{|c|}{$C 2$ (Lat.) } & \multicolumn{2}{|c|}{$C 2(\operatorname{Inf})}$. & \multicolumn{2}{|l|}{$C 3$} & \multicolumn{2}{|l|}{ C4 } & \multicolumn{2}{|l|}{$C 5$} & \multicolumn{2}{|l|}{ Có } & \multicolumn{2}{|l|}{$C 7$} \\
\hline & $R \%$ & $L \%$ & $R \%$ & $L \because$ & $R_{0}^{\circ}$ & $L \%$ & $R \%$ & $L \%$ & $R_{0}^{\circ}$ & $L \because$ & $R_{0}^{\circ}$ & $L: 0$ & $R^{\prime \prime}$ & $L \because$ & $R \%$ & $L \%$ \\
\hline Tspe 1 & 9.1 & 9.1 & 50.0 & 34.4 & 0 & 9.1 & 14.7 & 11.4 & 9.1 & 27.3 & 29.40 & 35.29 & 37.14 & 54.28 & 16.12 & 8.33 \\
\hline Type 2 & 24.2 & 36.4 & 6.2 & 12.5 & 18.7 & 6.1 & 0 & 2.8 & 0 & 3.0 & 0 & 0 & 2.85 & 5.71 & 0 & 0 \\
\hline Type 3 & 3.0 & 0 & 9.4 & 21.9 & 18.7 & 24.2 & 67.6 & 74.3 & 75.7 & 51.5 & 55.88 & 35.29 & 37.14 & 8.57 & 29.03 & 29.16 \\
\hline Type 4 & 57.6 & 6.1 & 15.6 & 25.0 & 37.5 & 21.2 & 17.6 & 0 & 15.1 & 3.0 & 8.82 & 11.76 & 11.42 & 8.57 & 6.45 & 54.10 \\
\hline Type 5 & 6.1 & 48.5 & 18.7 & 6.2 & 25.0 & 39.4 & 0 & 11.4 & 0 & 15.1 & 5.88 & 14.70 & 11.42 & 22.85 & 48.38 & 4.16 \\
\hline
\end{tabular}


Table 2 Minimal and maximal values for the length and breadth of the foramina transversaria in both sides of the various vertebrae

\begin{tabular}{|c|c|c|c|c|c|c|c|c|c|c|c|}
\hline \multirow[b]{2}{*}{ Vertebrae } & \multirow[b]{2}{*}{ Diameters $(\mathrm{mm})$} & \multicolumn{5}{|c|}{ Right } & \multicolumn{5}{|c|}{ Left } \\
\hline & & $N^{*}$ & Mean $\mp$ & $S D$ & $V$ & Range & $N$ & Mean if & $S D$ & $V$ & Range \\
\hline \multirow[t]{2}{*}{$\mathrm{Cl}$} & Length & 33 & 7.26 & 0.87 & 11.98 & $5.1-8.9$ & 33 & 7.23 & 0.98 & 13.55 & $5.4-8.9$ \\
\hline & Breadth & 33 & 5.52 & 0.93 & 16.16 & $3.8-7.6$ & 33 & 5.76 & 0.76 & 13.19 & $4.0-7.4$ \\
\hline \multirow{2}{*}{$\begin{array}{l}\text { C2 Lat. } \\
\text { App. }\end{array}$} & Length & 32 & 5.85 & 1.39 & 23.76 & $3.9-11.3$ & 32 & 5.76 & 0.71 & 12.33 & $4.0-7.3$ \\
\hline & Breadth & 32 & 4.77 & 0.70 & 14.68 & $3.6-6.2$ & 32 & 4.99 & 0.66 & 13.23 & $3.4-6.0$ \\
\hline \multirow{2}{*}{$\begin{array}{l}\text { C2 Inf. } \\
\text { App. }\end{array}$} & Length & 33 & 6.75 & 0.84 & 12.44 & $4.5-8.2$ & 33 & 7.50 & 1.17 & 15.60 & $4.7-10.8$ \\
\hline & Breadth & 32 & 5.26 & 0.76 & 14.45 & $3.4-6.6$ & 33 & 5.71 & 0.59 & 10.33 & $4.4-6.7$ \\
\hline \multirow[t]{2}{*}{$\mathrm{C} 3$} & Length & 35 & 6.22 & 0.66 & 10.60 & $4.6-7.7$ & 36 & 6.80 & 0.77 & 11.32 & $5.5-8.8$ \\
\hline & Breadth & 34 & 4.89 & 0.49 & 10.02 & $3.7-5.9$ & 35 & 5.15 & 0.51 & 9.90 & $4.1-6.0$ \\
\hline \multirow[t]{2}{*}{ C4 } & Length & 33 & 6.21 & 0.73 & 11.76 & $4.3-7.5$ & 35 & 6.58 & 0.80 & 12.16 & $5.1-8.7$ \\
\hline & Breadth & 35 & 4.99 & 0.61 & 12.22 & $3.4-6.0$ & 34 & 5.27 & 0.56 & 10.63 & $4.1-6.3$ \\
\hline \multirow[t]{2}{*}{ C5 } & Length & 34 & 6.14 & 0.95 & 15.47 & $2.5-7.6$ & 34 & 6.41 & 0.81 & 12.64 & $4.7-8.0$ \\
\hline & Breadth & 33 & 5.15 & 0.86 & 16.70 & $2.2-6.8$ & 34 & 5.57 & 0.96 & 17.24 & $3.5-7.5$ \\
\hline \multirow[t]{2}{*}{ C6 } & Length & 34 & 6.29 & 1.08 & 17.17 & $4.6-8.6$ & 35 & 6.40 & 1.74 & 27.19 & $2.6-10.8$ \\
\hline & Breadth & 33 & 5.04 & 1.00 & 18.57 & $3.0-7.5$ & 35 & 5.51 & 1.35 & 24.50 & $2.4-7.5$ \\
\hline \multirow[t]{2}{*}{ C7 } & Length & 31 & 6.31 & 2.01 & 31.85 & $2.0-10.6$ & 24 & 6.30 & 1.05 & 23.81 & $3.0-8.7$ \\
\hline & Breadth & 31 & 4.37 & 1.35 & 30.89 & $1.8-8.0$ & 24 & 4.58 & 1.28 & 28.00 & $2.4-8.0$ \\
\hline
\end{tabular}

* The discrepancy in foraminal numbers was due to the absence of the atlas and axis of three skeletons and to vertebrae either with missing foramina or foramina too small to be measured. In cases with double FT the diameter of the largest was used.

our calipers: four of $\mathrm{C} 7$, three of $\mathrm{C} 6$, and one of C5 vertebrae (Fig. 3).

\section{Double foramina}

Thirty-four vertebrae showed doubling of foramina transversaria. Of these, only six vertebrae (C6, C7) had FT of equal size, while the others (nineteen C6, five C5, and four C7 vertebrae) had an accompanying foramen of very small dimensions (Fig. 4).

\section{Triple foramina}

The single vertebra from the excavation (Fig. 5) is a bizarre case of triple FT. The anteromedial is large (mesomorph), the posterolateral smaller (mesomorph), and the median foramen small (dolichomorph).

\section{Absent foramen}

In three $\mathrm{C} 4$ and one $\mathrm{C} 6$ vertebrae, the process showed no FT.

\section{Osteophytic encroachments}

Fifteen FT showed osteophytic encroachment originating from the uncinate and articular processes (Figs. 7 and 8); nine from $\mathrm{C} 5$ and six from C6 vertebrae.

\section{Dissected specimen}

In one of the dissected specimens the vertebral artery is seen entering the FT of the third cervical vertebra (above the bifurcation of the common carotid artery), instead of entering from the sixth vertebra (Fig. 6).

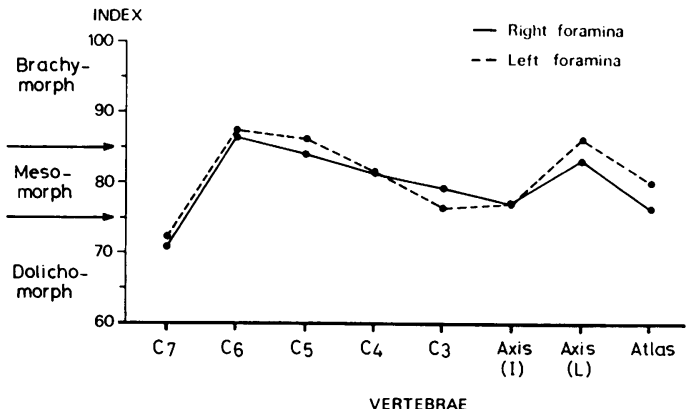

Fig. 2 Distribution of the mean indices of the foramina transversaria in each side of the various vertebrae.

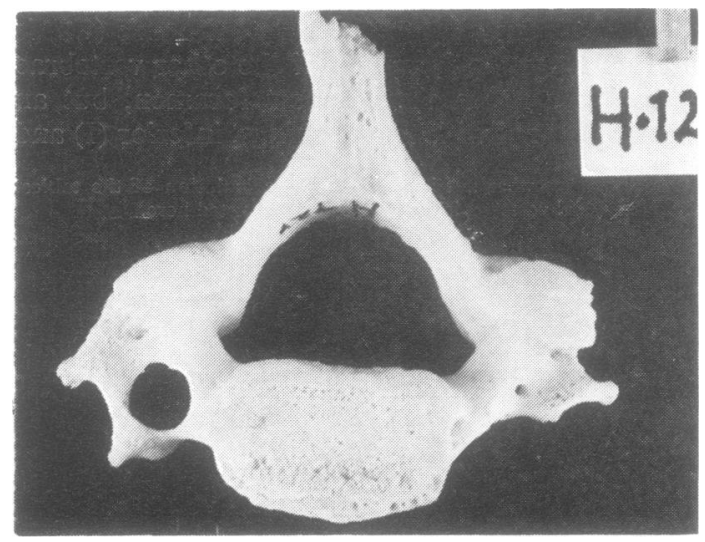

Fig. 3 C6 vertebra, inferior aspect. shows a very small right FT. The left FT is round (brachymorph) in type and of average size. 


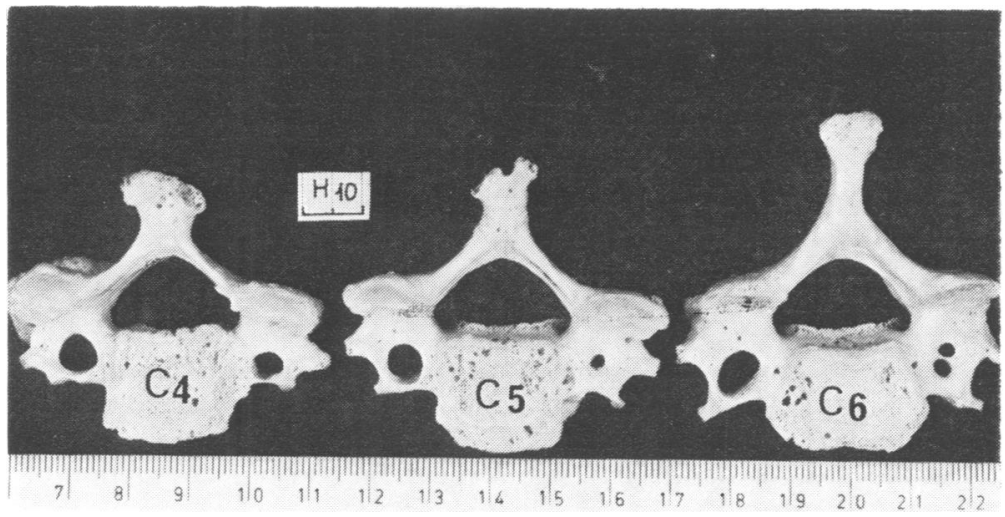

Fig. 4 Inferior view of $C 4, C 5, C 6$ vertebrae from the same vertebral column. Note the double FT of C6, single small FT of C5, and average size $F T$ of C4 vertebra on the right side. The left FT of C6 is an example of elliptic (dolychomorph) type with its longitudinal axis in a posteromedial direction. The left FT of C4 vertebra is oval (mesomorph) in type.

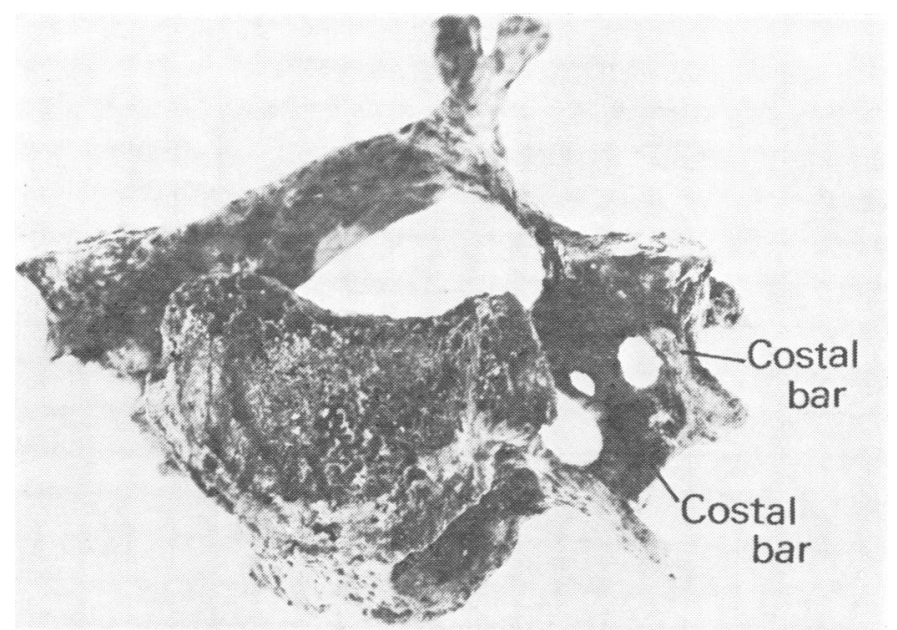

Fig. 5 Cervical vertebra (from an excavation in Israel), inferior view, showing triple FT. The anteromedial FT is large and oval; the posterolateral is smaller and oval, and the intermediate FT is small and elliptical. Two costal bars are present.

\section{Discussion and conclusions}

The most interesting finding in this study is the distribution of the FT which follow a kind of pattern at the different vertebral levels. It is suggested that, besides the embryological factors described in the formation of the foraminanamely, the fusion of the costal process to vertebrae-other anatomical or functional conditions may also play a role. Consideration should be given, among other factors, to the tensions and stresses imposed on the vessels running through the FT by the relatively free movements of the cervical spine (flexion, extension, and rotation).

In the literature (Tatlow and Bammer, 1957; Toussaint and Fabeck, 1966; Penning, 1968), it is acknowledged that normal extension and rotation of the head may impair blood flow in the vertebral artery, with constriction occurring in the vessel contralateral to the side of the rotation (at the atlantoaxial junction). Accompanying this rotation is a $10 \%$ change in length of the artery on the side contralateral to the direction of rotation.

As described, the inferior aperture of the axis shows a mesomorph (oval) type of foramen in contrast to a marked brachymorph (circular) form of the lateral aperture situated above it. This difference in shape may be related to the mechanical stresses due to movements. Pathological changes of the movements could therefore be expressed in changes of the foramina.

Hadley (1958) and Hyyppa et al. (1974) found that tortuosity of the vertebral artery may cause 
bone destruction. Thus, it may be a factor in the size of the foramina. Kovacs (1955) also described bony excavation on the anterior surface of the superior articular process by pressure of the vertebral artery. Since the vertebral vessels are a factor in the formation of the FT, it can be assumed that variations in the presence and course of the vessels will be manifested in changes of the FT. Conversely, variations of the FT can be useful for estimating changes or variations of the vessels and accompanying nerve structures. Stopford (1916) and Hardesty et al. (1963) have discussed the variability of the size of the vertebral arteries. Epstein (1969) found the arteries of the left side

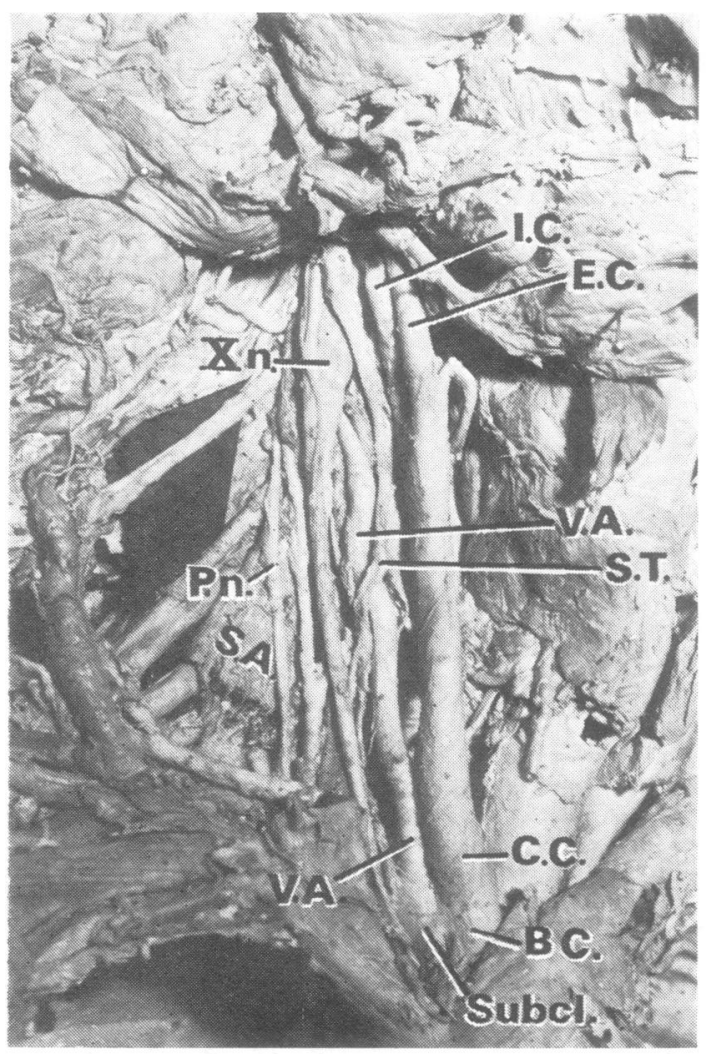

(a) bigger than those of the right. This fits our observation that the left FT are generally larger than the right FT.

An absence of FT could mean absence of vertebral arteries. A narrowing of the foramina could imply narrowness of the vessels, and so on. This concept cannot, however, be applied in a simple way. There are cases where the artery runs along the transverse process and not through the FT. This is particularly frequent in the lower cervical vertebrae. Instead of entering the sixth FT as normally occurs, the artery may start to enter the FT at higher levels, as previously mentioned in our description of a dissected speci-

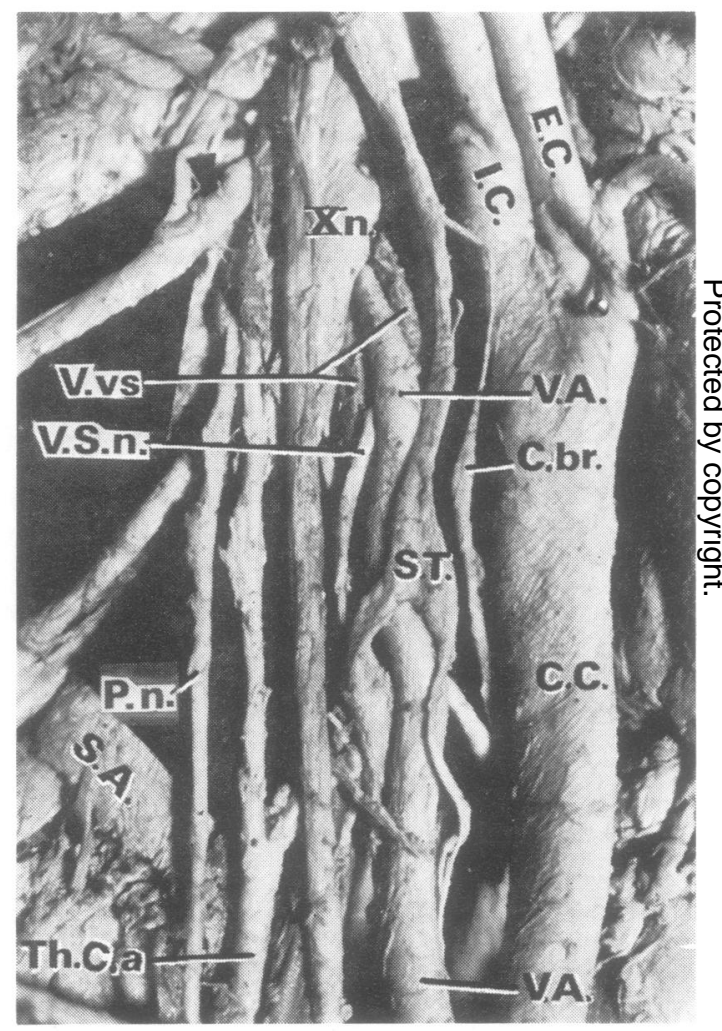

(b)

Fig. 6 A vertebral artery entering the FT at the level of C3 vertebra. (a) The vertebral artery takes its origin from the subclavian artery lateral to the common carotid artery. It runs parallel to the common carotid artery and leaves it at the level of C3 vertebra, a little above the bifurcation of the common carotid artery. The vertebral artery is seen splitting the sympathetic trunk, and on its upper lateral and medial side is accompanied by two vertebral veins. (b) An enlarged view of (a) shows the vertebral artery entering the FT at the level of C 3 vertebra accompanied by the two vertebral veins. A branch of the sympathetic nerve is seen accompanying the vessels towards the FT.

Abbreviations: V.A. = vertebral artery, C.C. $=$ common carotid artery, E.C. $=$ external carotid artery. I.C. $=$ internal carotid artery, B.C. $=$ brachiocephalic artery, Subcl. =subclavian artery, Th.C.a. = thyrocervical trunk of subclavian artery, V.vs. = vertebral veins, S.T. = sympathetic trunk, V.S.n. = vertebral sympathetic nerve, X.n. = vagus nerve, P.n. $=$ phrenic nerve, C.br. $=$ cardiac branch of sympathetic nerve. and $S . A .=$ scalenus anterior muscle. 
men (Fig. 6). We are not aware of the existence of cases where the artery, after starting normally through the FT leaves them for part of its course.

Other cases were described where the vertebral artery splits, one branch running through the FT and the other outside, to merge again in one simple trunk at upper levels. Kowada et al. (1973) observed fenestration of the vertebral artery occurring at the atlanto-occipital joint in 24 cases and intracranially in nine. Babin and Haller (1973) describe two vessels of unequal calibre arising separately from the subclavian artery and joining at the C6 vertebral level to form a vertebral artery of normal calibre. Epstein (1969) stresses the importance of the first and second FT as useful in the estimation of dilatation of the vertebral arteries.

The direct correlation between the size of the FT and the ariery should be questioned in certain cases. Many big FT may be due to the presence of big veins or simple connective tissue. This is normally the case of the FT in the seventh cervical ver:ebra, where the foramen is normally occupied only by the vertebral vein or veins. It should be noted here that the greatest variability in FT is found in this foramen. Similar questions should be raised regarding the double FT. Is one of the foramina occupied by the artery and the o:her by veins? Or is each FT occupied by branches of both vessels?

In this regard special mention must be made of the case presented in Fig. 4. The FT presents different sizes in the fourth, fifth, and sixth cervical vertebrae: the fourth is of normal average size, the fifth is very small, and the sixth has double small foramina. Possible variations of the vessels and their course as described above may perhaps provide an explanation for this kind of anatomical puzzle. The triple FT found in the vertebra from the excavations (Fig. 5) is a very unusual variation not previously encountered. It seems to be the result of a double rib bone element on the same side fusing to the original transverse process, thus resulting in the unusual number of FT. Therefore, it also shows two costal bars instead of one.

It is well known (Kovacs, 1955, Tatlow and Bammer, 1957; Sheehan et al., 1960) that impingement of osteophytes from the uncinate and articular processes are of utmost importance, as they can cause compression of the vertebral artery or irritation of the surrounding sympathetic plexus (Fig. 7 and 8 ). The most frequently affected FT were those of cervical vertebrae 5 and 6 . This corresponds to the area of the cervical spine where the osteophytes develop more frequently and reach the largest dimensions (Nathan, 1962).
It should be remembered that the vertebral and basilar arteries contribute to the blood supply not only of the brain, but also of the inner ear. Therefore, compression of the vertebral arteries or spasms of the same arteries due to irritation of the sympathetic plexuses may be manifested not only by neurological symptoms, but also by labyrinthine or hearing disturbances (Romanov et al., 1973).

The data provided by the present study on the variations of the FT can be helpful in the interpretation of radiographic pictures or in com-

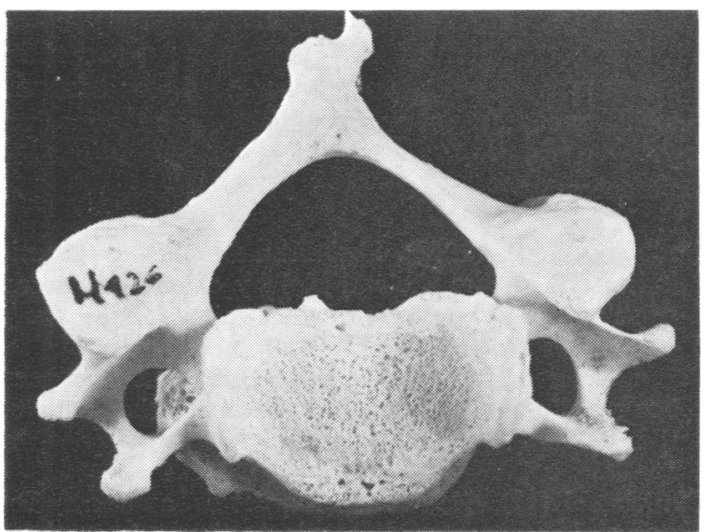

Fig. 7 C5 vertebra; superior view. One big osteophyte projecting from the inferior border of the vertebral body (Von Lushka's joint) is seen impinging on the right foramen transversarium.

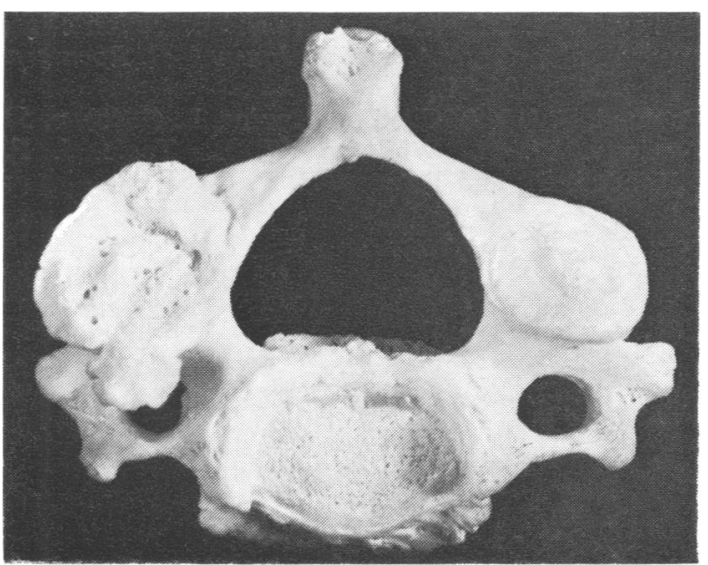

Fig. 8 C3 vertebra; superior view. The surface of the left articular process is smooth and its borders are clean (no arthritis), whereas the articular process on the right is irregular, cribrotic and with distinct lipping or osteophytes on its borders, all indicative of arthritis. One of these osteophytes impinges on the foramen transversarium. 
puterised axial tomography for diagnostic purposes in the conditions mentioned. They may also be of assistance in determining a more accurate surgical approach to the removal of osteophytes or spurs compressing the vertebral arteries, or for other interventions in the area (Cloward, 1958). More investigations o nthe subject, based especially on dissection of specimens, angiograms, and correlation of the findings with clinical symptoms are necessary to solve these problems.

Our special thanks are extended to Mrs J. Adler for her excellent drawings and help with the photographs, to Mrs M. Weissberger for technical assistance with the vertebrae, and to Mrs $L$. Efrati for correction and typing of the manuscript.

\section{References}

Anderson, J. E. (1968). Skeletal anomalies as genetic indicators on the skeletal biology of earlier human populations. Symposium of the Society for the Study of Human Biology, 8, 135-147.

Babin, E., and Haller, M. (1973). Correlation between bony radiological signs and dolichoarterial loops of the cervical vertebral artery. Neuroradiology, 7, 15-17.

Cloward, R. B. (1958). The anterior approach for removal of ruptured cervical discs. Journal of Neurosurgery, 15, 607-617.

Epstein, B. S. (1969). The Spine. A Radiological Text and Atlas. Third edition, pp. 24, 25, 65. Lea and Febiger: Philadelphia.

Exner, G. (1954). Cited by Penning, L. (1968), p. 50.

Hadley, L. A. (1958). Tortuosity and deflection of the vertebral artery. American Journal of Roentgenology, 80, 306-312.

Haglund, F. (1942). Cited by Penning, L. (1968), p. 50. Hardesty, W. H., Whitacre, W. B., Toole, J. F., Randall, P., and Royster, H. P. (1963). Studies on vertebral artery blood flow in man. Surgery, Gynecology, and Obstetrics, 116, 662-664.

Hyyppa, S. E., Laasonen, E. M., and Halonen, V. (1974). Erosion of cervical vertebrae caused by elongated and tortuous vertebral arteries. Neuroradiology, 7, 49-51.

Jaén, E. M. T. (1974). Variedades anatómicas en vértebras de la colección. Tlatelolco. Anales del Instituto Nacional de Antropologia y Historia, Mexico, Epoca $7^{a}$ Tomo IV, Volumen 52, 71-81.

Kovacs, A. (1955). Subluxation and deformation of the cervical apophyseal joints. A contribution to the aetiology of headache. Acta Radiologica, 43, 1-16.

Kowada, M., Takahashi, M., Gito, Y., and Kishikawa, T. (1973). Fenestration of the vertebral artery. Report of 2 cases demonstrated by angiography. Neuroradiology, 6, 110-112.

Nathan, H. (1962). Osteophytes of the vertebral column. An anatomical study of their development according to age, race and sex with considerations as to their etiology and significance. Journal of Bone and Joint Surgery, 44A, 243-268.

Penning, L. (1968). Functional Pathology of the Cervical Spine. Pp. 118-119. Excerpta Medica Foundation: Amsterdam.

Romanov, V. A., Miller, L. G., and Gaevyi, M. D. (1973). Effect of vertebral nerve on internal ear cochlear circulation. Bulletin of Experimental Biology and Medicine, 75, 10-12.

Sheehan, S., Bauer, R. B., and Meyer, J. S. (1960). Vertebral artery compression in cervical spondylosis. Arteriographic demonstration during life of vertebral artery insufficiency due to rotation and extension of the neck. Neurology (Minneapolis), 10, 968-986.

Stopford, J. S. B. (1916). The arteries of the pons and medulla oblongata. Journal of Anatomy (London), 50, 131-164.

Tatlow, T. W. F., and Bammer, H. G. (1957). Syndrome of vertebral artery compression. Neurology (Minneapolis), 7, 331-340.

Toussaint, J. P., and Fabeck, P. (1966). Cited by Penning, L. (1968), p. 53. 